\title{
Analisis CAR, BOPO, NPL, NIM, dan LDR Terhadap Pertumbuhan Kredit, serta Implikasinya pada Pertumbuhan Laba Bank (Suatu Penelitian pada Periode 2001-2010)
}

\author{
Yenni Yuniangsih ${ }^{1}$
}

\begin{abstract}
Abstrak
Penelitian ini bertujuan untuk mengetahui pengaruh CAR, BOPO, NPL, NIM, dan LDR terhadap pertumbuhan kredit, serta implikasinya pada pertumbuhan laba Bank Pemerintah Periode 2001-2010.

Metode pengambilan sampel menggunakan metode purposive sampling. Jumlah populasi 130, dengan jumlah sampel sebanyak 4 bank pemerintah yang memiliki laporan keuangan periode Januari 2001 sampai dengan Desember 2010. Pengujian hipotesis menggunakan analisis jalur, yang dibantu program SPSS, dengan terlebih dahulu melakukan uji asumsi klasik yang meliputi uji multikolinearitas, heterokedastisitas, dan autokorelasi.

Hasil penelitian menunjukkan, Secara keseluruhan CAR (X1), BOPO (X2), NPL (X3), NIM (X4), dan LDR (X5) tidak berkontribusi secara signifikan terhadap terhadap pertumbuhan kredit (Y1). Demikian pula CAR (X1), BOPO (X2), NPL (X3), NIM (X4), dan LDR (X5) tidak berkontribusi secara signifikan terhadap pertumbuhan kredit (Y1) serta implikasinya pada pertumbuhan laba (Y2). Secara parsial BOPO (X2) dan NPL (X3) berkontribusi secara signifikan terhadap pertumbuhan laba (Y2) masing-masing sebesar 12.88\% dan 17.64\%.
\end{abstract}

\section{Kata Kunci : BOPO, CAR, LDR, NIM, NPL, Pertumbuhan Kredit, Pertumbuhan Laba Bank}

\section{Pendahuluan}

Industri perbankan memegang peranan penting dalam menunjang kegiatan perekonomian. Begitu penting perannya sehingga ada anggapan bahwa bank merupakan "nyawa" untuk menggerakkan roda perekonomian suatu negara. Karena fungsi bank sangatlah vital, diantaranya dalam hal penciptaan uang, mengedarkan uang, menyediakan uang untuk menunjang kegiatan usaha, tempat mengamankan uang, tempat melakukan investasi, dan jasa keuangan lainnya.

Kurun waktu 2001-2010 merupakan tahun yang penuh dinamika bagi industri perbankan nasional. Berbagai langkah konsolidasi internal dan program restrukturisasi perbankan yang telah dilaksanakan sejak beberapa tahun yang lalu terus menunjukkan perkembangan yang positif. Hal ini tercermin pada kuatnya struktur modal, menurunnya resiko kredit dan meningkatnya profitabilitas perbankan. Bank milik pemerintah seperti Bank Mandiri, BNI, BRI dan BTN menguasai pangsa asset di atas 8\% di mana tertinggi diduduki oleh Bank Mandiri sebesar 18,86\% (Bank Indonesia 2008).
Pertumbuhan perbankan Indonesia pada 2005 mengalami tantangan yang berat akibat inflasi dan suku bunga bank yang tinggi. Kondisi ini kian diperberat dengan permintaan $\mathrm{Bl}$ agar perbankan tidak menaikkan suku bunga bank untuk menjaga pertumbuhan ekonomi tetap berjalan (KapanLagi.com 2005). Hal ini membuat bank menjalankan fungsinya sebagai lembaga intermediasi dan berorientasi pada penciptaan nilai tambah ataupun laba dengan menerapkan prudential banking atau kehati-hatian.

Kredit merupakan bisnis utama suatu bank dan sumber pendapatan utama bagi bank tetapi juga mengandung resiko yang paling besar pula. Pertumbuhan kredit tersebut masih belum menunjukkan meningkatnya fungsi intermediasi perbankan yang optimal. Rendahnya pertumbuhan kredit di satu sisi disebabkan persepsi perbankan terhadap tingginya risiko sektor riil yang masih terimbas krisis keuangan global.

Adapun pertumbuhan kredit pada tahun 2010 mengalami kenaikan menjadi 21,56\% dibandingkan periode tahun 2009 sebesar 21,26\%. Pertumbuhan kredit 
tak terlepas dari kinerja yang dihasilkan. Peningkatan kinerja keuangan mempunyai dampak yang luar biasa kepada usaha menjaga kepercayaan nasabah agar tetap setia menggunakan jasanya (Sofyan 2003).

Selama tahun 2010, perbankan Indonesia berhasil membukukan laba bersih sebesar Rp. 57,3 triliun. Jumlah itu tumbuh 26,8\% dibandingkan pencapaian laba tahun sebelumnya yang mencapai Rp. 45,2 triliun (Bank Indonesia 2008).

Rasio yang digunakan dalam perbandingan kinerja keuangan bank meliputi: CAR, BOPO, NPL, NIM, dan LDR karena dinilai mempengaruhi kinerja keuangan. Bahwa CAR, BOPO, NPL, NIM, dan LDR berpengaruh secara signifikan terhadap ROA yang merupakan proksi dari kinerja keuangan (Mahardian 2008).

Rasio pertama yaitu rasio permodalan yang diwakili oleh variabel rasio CAR (Capital Adequacy Ratio), yaitu rasio keuangan yang berkaitan dengan permodalan perbankan dimana besarnya modal suatu bank akan berpengaruh pada mampu atau tidaknya suatu bank secara efisien menjalankan kegiatannya. Jika modal yang dimiliki oleh bank tersebut mampu menyerap kerugian-kerugian yang tidak dapat dihindarkan, maka bank dapat mengelola seluruh kegiatannya secara efisien, sehingga kekayaan bank (kekayaan pemegang saham) diharapkan akan semakin meningkat demikian juga sebaliknya (Muljono 1999).

Kedua, rasio biaya/efisiensi bank, yang diwakili oleh variabel rasio BOPO (Biaya Operasional terhadap Pendapatan Operasional), merupakan perbandingan antara total biaya operasi dengan total pendapatan operasi. Efisiensi operasi dilakukan oleh bank dalam rangka untuk mengetahui apakah bank dalam operasinya yang berhubungan dengan usaha pokok bank, dilakukan dengan benar (sesuai dengan harapan pihak manajemen dan pemegang saham) serta digunakan untuk menunjukkan apakah bank telah menggunakan semua faktor produksinya dengan tepat guna dan berhasil guna (Mawardi 2005).

Ketiga, rasio kualitas aktiva produktif, yang diwakili oleh NPL (Non Performing Loan), merupakan rasio keuangan yang bekaitan dengan risiko kredit. Risiko kredit adalah risiko dari kemungkinan terjadinya kerugian bank sebagai akibat dari tidak dilunasinya kembali kredit yang diberikan bank kepada debitur. Non Performing Loan adalah perbandingan antara total kredit bermasalah dengan total kredit yang di berikan kepada debitur. Bank dikatakan mempunyai NPL yang tinggi jika banyak kredit yang bermasalah. Apabila suatu bank mempunyai NPL yang tinggi, maka akan memperbesar biaya, baik biaya pencadangan aktiva produktif maupun biaya lainnya, dengan kata lain semakin tinggi NPL suatu bank, maka hal tersebut akan mengganggu kinerja bank tersebut (Ali 2006).

Keempat, Net Interest Margin (NIM) mencerminkan resiko pasar yang timbul karena adanya pergerakan variabel pasar, dimana hal tersebut dapat merugikan bank. Berdasarkan peraturan Bank Indonesia salah satu proksi dari risiko pasar adalah suku bunga, yang diukur dari selisih antara suku bunga pendanaan (funding) dengan suku bunga pinjaman yang diberikan (lending) atau dalam bentuk absolut adalah selisih antara total biaya bunga pendanaan dengan total biaya bunga pinjaman dimana dalam istilah perbankan disebut Net Interest Margin (NIM) (Mawardi 2005).

Dan kelima, rasio Likuiditas, yang diwakili oleh variabel rasio LDR (Loan to Deposit Ratio), merupakan rasio yang mengukur kemampuan bank untuk memenuhi kewajiban yang harus dipenuhi. Sehingga semakin tinggi LDR maka laba bank semakin meningkat (dengan asumsi bank tersebut mampu menyalurkan kreditnya dengan efektif), dengan meningkatnya laba bank, maka kinerja bank juga meningkat. Dengan demikian besar-kecilnya rasio LDR suatu bank akan mempengaruhi kinerja bank tersebut.

Pergerakan CAR (Capital Adequacy Ratio) sangat fluktuatif, Hal serupa juga terjadi pada tingkat efisiensi operasi perbankan, dimana perolehan BOPO dari Juni 2001 sampai Juni 2010 tidak menentu arahnya atau bisa dikatakan berfluktuasi.

Fenomena antar rasio-rasio keuangan juga terjadi terhadap NPL. Dari Juni 2001 hingga Juni 2009, angka NPL mempunyai kecenderungan menurun. Sehingga secara umum dapat disimpulkan bahwa rasio NPL perbankan yang tercatat di BEJ pada periode tersebut semakin baik karena pada periode terakhir yaitu Desember 2009, walaupun pada awal tahun 2010 mengalami kenaikan. Dengan kata lain kredit bermasalah yang dihadapi bank-bank pada periode tersebut semakin kecil. Mengenai pergerakan rasio NIM, rasio NIM bank-bank 
yang tercatat di BEJ periode 2001 hingga 2010 tidak ada yang memenuhi standar yang ditetapkan Bank Indonesia yaitu diatas 6\% (Infobank, 2007). Pada periode tersebut angka NIM berfluktuasi, jadi dapat disimpulkan bahwa perbandingan pendapatan bunga bersih dengan rata-rata aktiva produktif bank-bank berada pada kondisi kurang baik. Pada pergerakan rasio LDR terjadi fluktuasi namun masih memenuhi standar LDR menurut Bank Indonesia adalah 80\% hingga 110\% (Achmad 2003).

Melihat dinamika rasio CAR, BOPO, NPL, NIM, dan LDR yang tidak menentu selama periode sepuluh tahun (2001-2010), maka penelitian ini untuk menganalisis CAR, BOPO, NPL, NIM, dan LDR terhadap pertumbuhan kredit, serta implikasinya pada pertumbuhan laba bank.

\section{Kerangka Pemikiran}

Kredit merupakan bisnis utama suatu bank dan sumber pendapatan utama bagi bank tetapi juga mengandung resiko yang paling besar pula. Kualitas kredit harus bisa dinilai secara transparan, sehingga bila kita perlu memperhatikan laporan keuangan Bank. Kinerja bank yang baik bisa menyebabkan kepercayaan manajemen ataupun stake holders meningkat karena berarti bank tersebut memiliki kemampuan untuk meningkatkan bisnis.

Rasio yang digunakan dalam penelitian ini yang meliputi: pertama, rasio permodalan yang diwakili oleh variabel rasio CAR (Capital Adequacy Ratio) yaitu rasio keuangan yang berkaitan dengan permodalan perbankan dimana besarnya modal suatu bank akan berpengaruh pada mampu atau tidaknya suatu bank secara efisien menjalankan kegiatannya, rasio NPL (Non Performing Loan) merupakan rasio keuangan yang bekaitan dengan risiko kredit, rasio BOPO merupakan perbandingan antara total biaya operasi dengan total pendapatan operasi, rasio Net Interest Margin (NIM) mencerminkan resiko pasar yang timbul karena adanya pergerakan variabel pasar, dimana hal tersebut dapat merugikan bank, dan terakhir rasio LDR (Loan to Deposit Ratio) merupakan rasio yang mengukur kemampuan bank untuk memenihi kewajiban yang harus dipenuhi.

Pandangan komprehensif tentang penelitian ini dan pola pengaruh antar variabel menurut variabel penelitian dapat divisualisasikan melalui paradigma pemikiran pada Gambar 1 sebagai berikut:

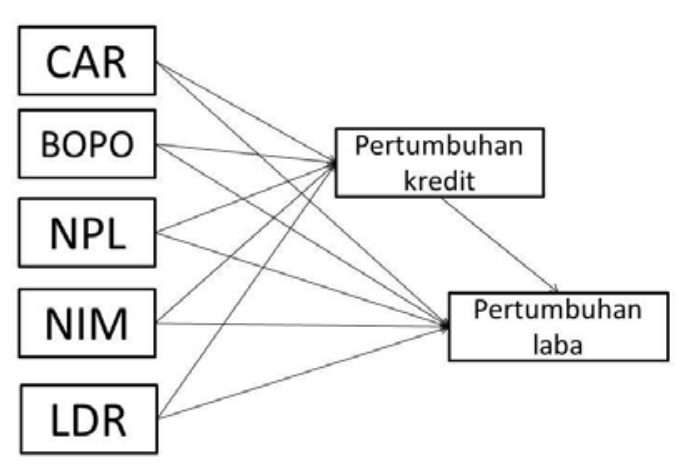

\section{Gambar 1 Paradigma Pemikiran}

\subsection{Hipotesis Penelitian}

Hipotesis penelitian dirumuskan dalam beberapa point sebagai berikut:

1. Capital Adequacy Ratio berpengaruh terhadap pertumbuhan kredit.

2. BOPO berpengaruh terhadap pertumbuhan kredit.

3. Non Performing Loan berpengaruh terhadap pertumbuhan kredit.

4. Net Interest Margin berpengaruh terhadap pertumbuhan kredit.

5. Loan to Deposit Ratio berpengaruh terhadap pertumbuhan kredit.

6. Capital Adequacy Ratio berpengaruh terhadap pertumbuhan laba bank.

7. BOPO berpengaruh terhadap pertumbuhan laba bank.

8. Non Performing Loan berpengaruh terhadap pertumbuhan laba bank.

9. Net Interest Margin berpengaruh terhadap pertumbuhan laba bank.

10. Loan to Deposit Ratio terhadap pertumbuhan laba bank.

\section{Metode Penelitian}

Metode penelitian yang digunakan dalam penelitian ini menggunakan pendekatan deskriptif (descriptive analysis), Metode penelitian yang digunakan adalah explanatory research atau penelitian penjelasan karena bersifat penjelasan, yaitu menjelaskan hubungan kausalitas.

Variabel bebas yang dimaksud dalam penelitian ini adalah variabel CAR (X1), BOPO (X2), NPL (X3), NIM (X4), dan LDR (X5). Sedangkan yang dimaksud variabel terikat 
adalah pertumbuhan kredit (Y1) dan pertumbuhan laba bank (Y2).

Populasi dalam penelitian ini adalah 130 bank. Untuk pengambilan sampel dari populasi agar diperoleh sampel yang representatif dan mewakili, maka penarikan sampel berdasarkan metode purposive sampling dengan cara memilih Bank Pemerintah yang memiliki laporan keuangan lengkap selama periode Januari 2001 hingga Desember 2010. Sesuai dengan kriteria di atas, banyaknya bank yang diamati adalah 4 bank yaitu BNI, BRI, BTN, dan Mandiri.

Analisis data yang digunakan penulis adalah analisis jalur (path analysis).

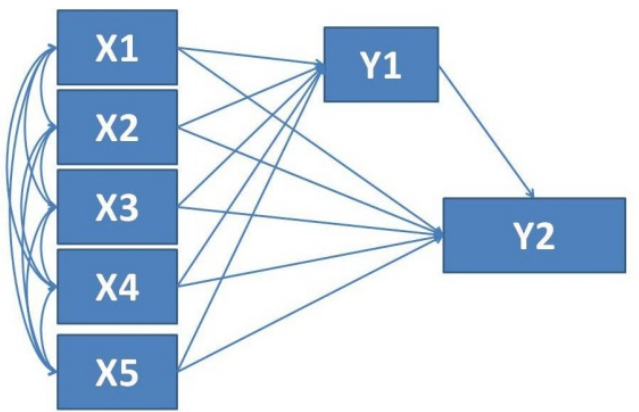

\section{Gambar 2 Struktur Model penelitian}

Keterangan :

$\mathrm{X} 1=\mathrm{CAR}$

$\mathrm{X} 2=\mathrm{BOPO}$

$\mathrm{X} 3=\mathrm{NPL}$

$X 4=N I M$

$X 5=L D R$

$\mathrm{Y} 1=$ Pertumbuhan Kredit

Y2 = Pertumbuhan Laba Bank

Formula untuk menghitung koefisien korelasi menggunakan Pearson's Cofficient of Correlation (Product Moment Coefficient.

\section{Hasil Pengutian}

\subsection{Pengujian Koefisien Jalur Sub struktur I}

Hipotesis penelitian berikut:

a. Capital Adequacy Ratio berpengaruh terhadap pertumbuhan kredit

b. BOPO pada berpengaruh terhadap pertumbuhan kredit c. Non Performing Loan berpengaruh terhadap pertumbuhan kredit

d. Net Interest Margin berpengaruh terhadap pertumbuhan kredit

e. Loan to Deposit Ratio berpengaruh terhadap pertumbuhan kredit

Rumusan hipotesis di atas bila diterjemahkan ke dalam diagram jalur tampak pada Gambar 3 sebagai berikut:

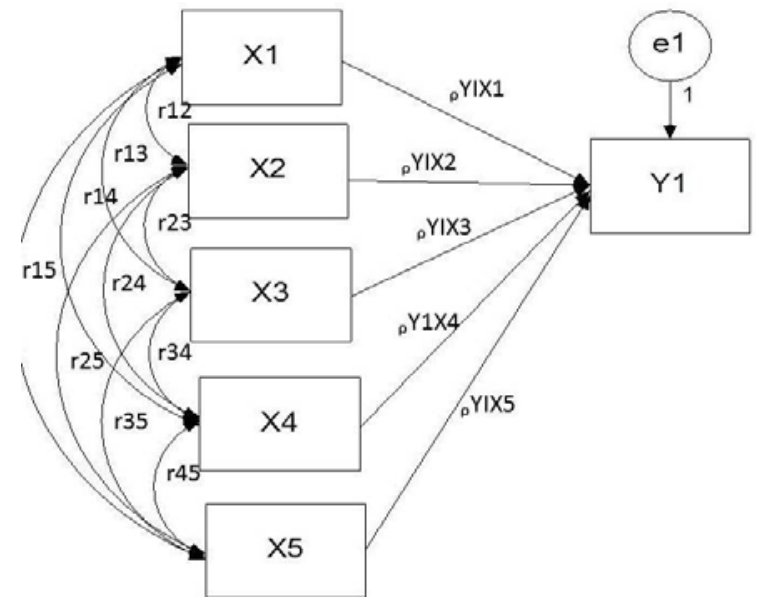

\section{Gambar 3 Struktur hubungan kausal $X 1, X 2, X 3, X 4, X 5$, dan Y1}

Persamaan struktural sub-struktur 1 dinyatakan oleh:

$Y_{1}=\rho_{y 1 \times 1} X_{1}-\rho_{y 1 \times 2} X_{2}-\rho_{y 1 \times 3} X_{3}+\rho_{y 1 \times 4} X_{4}+\rho_{y 1 \times 5} X_{5}+e_{1}$

\subsubsection{Pengujian secara keseluruhan}

uji secara keseluruhan hipotesis statistiknya sebagai berikut:

$$
\begin{aligned}
\mathrm{H}_{0}= & \rho_{y 1 \times k}=\rho_{y 1 x 2}=\rho_{y 1 \times 3}=\rho_{y 1 \times 4}=\rho_{y 1 x 5}=0 \\
H_{1}= & \text { sekurang-kurangnya ada sebuah } \\
& \rho_{y 1 x k} \neq 0, k=1,2,3,4,5
\end{aligned}
$$

Berdasarkan hasil uji ANOVA diperoleh nilai F untuk model 1 sebesar 2,139 dengan nilai $P=0.084$. karena nilai $\mathrm{P}>0.05$ maka keputusannya adalah $\mathrm{H}_{0}$ diterima. 


\subsection{2 pengujian secara individual}

ujisecara individual ditunjukkan oleh tabel coefficient. Hipotesis penelitian yang hendak diuji dirumuskan menjadi hipotesis statistik sebagai berikut :

$\mathrm{H}_{0}=\rho_{y 1 x k}=0 ; \mathrm{CAR}, \mathrm{BOPO}, \mathrm{NPL}, \mathrm{NIM}$, LDR tidak berpengaruh terhadap pertumbuhan kredit

$\mathrm{H}_{1}=\rho_{y 1 x k}>0 ; \mathrm{CAR}, \mathrm{BOPO}, \mathrm{NPL}, \mathrm{NIM}, \mathrm{LDR}$ berpengaruh terhadap pertumbuhan kredit

Dari tabel coefficient diperoleh informasi bahwa koefisien jalur X1 ke Y1, X2 ke Y1, X3 ke Y1, X4 ke Y1, dan $X 5$ ke $Y 1$ secara statistik tidak signifikan karena nilai P> 0.05. Model I ini tidak melakukan trimming karena semua variabel tidak berpengaruh.

\subsection{Pengujian Koefisien Jalur Sub struktur II}

Hipotesis penelitian berikut:

a. Capital Adequacy Ratio berpengaruh terhadap pertumbuhan laba.

b. BOPO berpengaruh terhadap pertumbuhan laba

c. Non Performing Loan berpengaruh terhadap pertumbuhan laba.

d. Net Interest Margin berpengaruh terhadap pertumbuhan laba.

e. Loan to Deposit Ratio berpengaruh terhadap pertumbuhan laba.

Rumusan hipotesis di atas bila diterjemahkan ke dalam diagram jalur tampak sebagai berikut:

\section{Gambar 4}

Struktur hubungan kausal

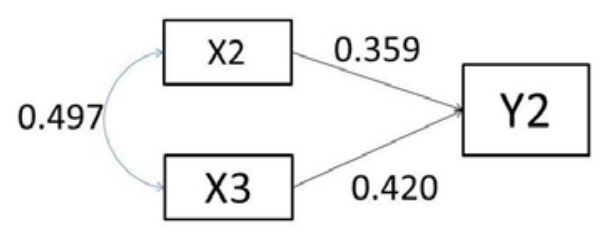

\section{$X 1, X 2, X 3, X 4, X 5, Y 1$ dan Y2}

Persamaan struktural sub-struktur 1 dinyatakan oleh:

$$
Y_{2}=\rho_{y 2 \times 1} X_{1}-\rho_{y 2 \times 2} X_{2}-\rho_{y 2 \times 3} X_{3}+\rho_{y 2 \times 4} X_{4}+\rho_{y 2 \times 5} X_{5}+\rho_{y 2211} Y_{1}+e_{1}
$$

\subsection{1 pengujian secara keseluruhan}

uji secara keseluruhan ditunjukkan oleh hipotesis statistiknya sebagai berikut :

$$
\begin{aligned}
H_{0}= & \rho_{y 2 \times k}=\rho_{y 2 \times 2}=\rho_{y 2 \times 3}=\rho_{y 2 \times 4}=\rho_{y 2 \times 5}=\rho_{y 2 y 1}=0 \\
H_{1}= & \text { sekurang-kurangnya ada sebuah } \\
& \rho_{y 1 x k} \neq 0, k=1,2,3,4,5
\end{aligned}
$$

Berdasarkan hasil uji ANOVA diperoleh nilai $F$ untuk model 1 sebesar 1.926 dengan nilai $P=0.106$. karena nilai $\mathrm{P}>0.05$ maka keputusannya adalah $\mathrm{H}_{0}$ diterima.

\subsection{2 pengujian secara individual}

Uji secara individual ditunjukkan oleh tabel coefficient. Hipotesis penelitian yang hendak diuji dirumuskan menjadi hipotesis statistik sebagai berikut :

$H_{0}=\rho_{y 1 x k}=0 ; \mathrm{CAR}, \mathrm{BOPO}, \mathrm{NPL}, \mathrm{NIM}, \mathrm{LDR}$, pertumbuhan kredit tidak berpengaruh terhadap pertumbuhan laba

$H_{1}=\rho_{y 1 x k}>0 ; \mathrm{CAR}, \mathrm{BOPO}, \mathrm{NPL}, \mathrm{NIM}, \mathrm{LDR}$, pertumbuhan kredit berpengaruh terhadap pertumbuhan laba

Dari tabel coefficient diperoleh informasi bahwa :

- $\quad$ koefisien jalur X1 ke Y2, X4 ke Y2, X5 ke Y2, dan $Y 1$ ke $Y 2$ secara statistik tidak signifikan karena nilai $P>0.05$.

- $\quad$ koefisien jalur X2 ke Y2 dan X3 ke Y2 secara statistik signifikan karena nilai $P<0.05$.

Oleh karena ada koefisien jalur yang tidak signifikan maka model perlu di trimming, yaitu men-drop atau mengeluarkan variabel X1 ke Y1, X4 ke Y1, X5 ke Y,dan $Y 1$ ke $Y 2$ yang koefisien jalurnya tidak signifikan dari analisis selanjutnya.

Hasil trimming dijelaskan oleh Gambar 5 besarnya koefisien X2 ke Y2 dan X3 ke Y2 berubah masing-masing $\rho Y 2 X 2=0.359$ (12.88\%) dan $\rho Y 2 X 2=-0.420$ (17.64\%). Besarnya koefien determinasi X2 ke Y2 dan X3 ke $Y 2$ adalah $15.5 \%$. 


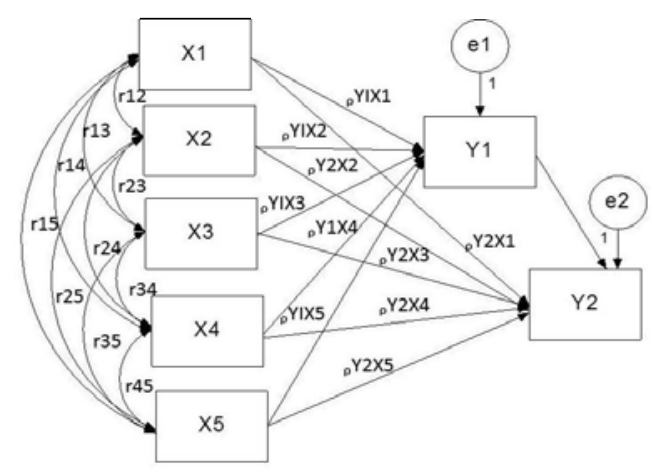

Gambar 5

Struktur hubungan kausal X2, X3 dan Y2

5. Pembahasan Hasil Penelitian

\subsection{Pengaruh CAR, BOPO, NPL, NIM, dan LDR terhadap Pertumbuhan Kredit}

Secara keseluruhan CAR (X1), BOPO (X2), NPL (X3), NIM (X4), dan LDR (X5) tidak berkontribusi secara signifikan terhadap pertumbuhan kredit (Y1). Begitu pun secara parsial, CAR (X1), BOPO (X2), NPL (X3), NIM (X4), dan LDR (X5) tidak berpengaruh pada pertumbuhan kredit (Y1).

\subsection{Pengaruh CAR, BOPO, NPL, NIM, dan LDR terhadap Pertumbuhan Kredit serta Implikasinya pada Pertumbuhan Laba}

Secara keseluruhan CAR (X1), BOPO (X2), NPL (X3), NIM (X4), dan LDR (X5) tidak berkontribusi secara signifikan terhadap pertumbuhan kredit (Y1) serta implikasinya pada pertumbuhan laba (Y2). Secara parsial, CAR (X1), NIM (X4), LDR (X5), dan pertumbuhan kredit (Y1) tidak berpengaruh pada pertumbuhan laba. Tapi BOPO (X2) dan NPL (X3) berkontribusi secara signifikan terhadap pertumbuhan kredit (Y1) serta implikasinya pada pertumbuhan laba (Y2).

\section{Kesimpulan}

1. Capital Adequacy Ratio (CAR) tidak berpengaruh terhadap pertumbuhan kredit artinya besar kecilnya rasio CAR tidak berkontribusi secara signifikan terhadap pertumbuhan kredit.

2. Efisiensi operasi (BOPO) tidak berpengaruh terhadap pertumbuhan kredit artinya besar kecilnya rasio BOPO tidak berkontribusi secara signifikan terhadap pertumbuhan kredit.

3. Non Performing Loan (NPL) tidak berpengaruh terhadap pertumbuhan kredit artinya besar kecilnya rasio NPL tidak berkontribusi secara signifikan terhadap pertumbuhan kredit.

4. Net Interest Margin (NIM) tidak berpengaruh terhadap pertumbuhan kredit artinya besar kecilnya rasio NIM tidak berkontribusi secara signifikan terhadap pertumbuhan kredit.

5. Loan to Deposit Ratio (LDR) tidak berpengaruh terhadap pertumbuhan kredit artinya besar kecilnya rasio LDR tidak berkontribusi secara signifikan terhadap pertumbuhan kredit.

6. Capital Adequacy Ratio (CAR) tidak berpengaruh terhadap pertumbuhan laba bank artinya besar kecilnya rasio CAR tidak berkontribusi secara signifikan terhadap pertumbuhan laba bank.

7. Efisiensi operasi (BOPO) berpengaruh terhadap pertumbuhan laba bank sebesar 12,88\% artinya rasio BOPO berkontribusi secara signifikan terhadap pertumbuhan laba bank sebesar 12,88\%.

8. Non Performing Loan (NPL) berpengaruh terhadap pertumbuhan laba bank sebesar 17,64\% artinya rasio NPL berkontribusi secara signifikan terhadap pertumbuhan laba bank sebesar 17,64\%.

9. Net Interest Margin (NIM) tidak berpengaruh terhadap pertumbuhan laba bank artinya besar kecilnya rasio NIM tidak berkontribusi secara signifikan terhadap pertumbuhan laba bank.

10. Loan to Deposit Ratio (LDR) tidak berpengaruh terhadap pertumbuhan laba bank artinya besar kecilnya rasio LDR tidak berkontribusi secara signifikan terhadap pertumbuhan laba bank.

\section{Rekomendasi}

1. Untuk peneliti yang akan meneliti lebih lanjut penulis menyarankan untuk lebih jauh menganilisis mengenai pengaruh rasio-rasio keuangan $\mathrm{CAR}, \mathrm{BOPO}, \mathrm{NPL}$, NIM, dan LDR dengan menambah sampel (jumlah bank yang diteliti lebih banyak dengan menggunakan periode penelitian yang cukup panjang misalnya sepuluh tahun ke atas.

2. Dalam penelitian ini hanya variabel yang berkaitan dengan laporan keuangan yang diteliti pengaruhnya, 
maka untuk penelitian selanjutnya dapat dilakukan dengan memperhatikan faktor-faktor lain yang mungkin berpengaruh tetapi tidak dimasukkan ke dalam penelitian ini, misalnya faktor permintaan masyarakat terhadap kredit, faktor pendapatan masyarakat, faktor tingkat suku bunga, nilai tukar mata uang, gejolak di perbankan, seperti Peraturan Pemerintah serta corporate action, seperti divestasi, pembagian deviden, merger, dan lain-lain.

\section{Daftar Pustaka}

Achmad, Tarmizi \& Willyanto K. Kusumo, 2003. Analisis Rasio-RasioKeuangan sebaai Indikator dalam Memprediksi Potensi Kebangkrutan Perbankan di Indonesia, Media Ekonomi dan Bisnis, Vol. XV, No.1, Juni, pp. 54-75.

Ali, Masyhud, 2006. Manajemen Risiko: Strategi Perbankan dan Dunia Usaha Menghadapi Tantangan Globalisasi Bisnis, Rajawali Pers, Jakarta.

Bank Indonesia, 2004, Laporan Keuangan Publikasi Triwulanan, www.bi.go.id

, 2005, Laporan Keuangan Publikasi Triwulanan, www.bi.go.id

, 2006, Laporan Keuangan Publikasi Triwulanan, www.bi.go.id

2007, Laporan Keuangan Publikasi Triwulanan, www.bi.go.id

, 2008, Laporan Keuangan Publikasi Triwulanan, www.bi.go.id

, 2009, Laporan Keuangan Publikasi Triwulanan, www.bi.go.id

, 2010, Laporan Keuangan Publikasi Triwulanan, www.bi.go.id

Mawardi, Wisnu, 2005. Analisis Faktor Faktor yang Mempengaruhi Kinerja Keuangan Bank Umum di Indonesia (Studi Kasus pada Bank Umum dengan
Total Asset Kurang dari 1 Triliun). Jurnal Bisnis Strategi, Vol. 14, No. 1, Juli, pp. 83-94.

Peraturan Bank Indonesia No. 5/8/PBI/2003, Penerapan Manajemen Risiko bagi Bank Umum.

Surat Edaran Bank Indonesia No. 3/30 DPNP tgl. 14 Desember 2001. Perihal: Laporan Keuangan Publikasi Bank Umum kepada Bank Indonesia, Bank Indonesia, Jakarta.

Surat Edaran Bank Indonesia No. 6/73/Intern DPNP tgl. 24 Desember 2004, Perihal: Pedoman Sistem Penilaian Tingkat Kesehatan Bank Umum (CAMELS Rating), Bank Indonesia, Jakarta.

Syofyan, Sofriza, 2002. Pengaruh Struktur Pasar terhadap Kinerja Perbankan di Indonesia. Media Riset Bisnis \& Manajemen, Vol. 2, No. 3, Desember, pp. 194219.

Mahardian, Pandu. 2008. Analisis Pengaruh Rasio CAR, BOPO, NPL, NIM dan LDR Terhadap Kinerja Keuangan Perbankan, (Studi Kasus Perusahaan Perbankan yang tercatat di BEJ Periode Juni 2002 - Juni 2007). Universitas Dipenogoro. Semarang. 